Review began 12/18/2021 Review ended 12/30/2021 Published 01/05/2022

๑) Copyright 2022 Lim et al. This is an open access article distributed under the terms of the Creative Commons Attribution License CC-BY 4.0. which permits unrestricted use, distribution, and reproduction in any medium, provided the original author and source are credited.

\section{A Case of Intracardiac Thrombus in a Recovery Coronavirus Disease 2019 (COVID-19) Patient}

\author{
William Lim ${ }^{1}$, Swann Tin ${ }^{1}$, May Breitling ${ }^{1}$, Richard Grodman ${ }^{2}$, Keith Diaz ${ }^{3}$ \\ 1. Internal Medicine, Richmond University Medical Center, New York, USA 2. Cardiology, Richmond University Medical \\ Center, New York, USA 3. Pulmonary and Critical Care, Richmond University Medical Center, New York, USA
}

Corresponding author: William Lim, wlim@rumcsi.org

\begin{abstract}
Coronavirus disease 2019 (COVID-19) was thought to mainly affect the respiratory system. However, studies have shown that it can be associated with hypercoagulability leading to thromboembolism. Although venous thromboembolism is a common complication associated with COVID-19, arterial thrombosis and intracardiac thrombosis are not frequently described. We herein report a case of a 54-year-old male with a past medical history of end-stage renal disease, diabetes mellitus, hypertension, heart failure, chronic obstructive pulmonary disease who presented to the emergency department with shortness of breath and was found to have intracardiac thrombus in post-recovery COVID-19 state.
\end{abstract}

Categories: Cardiology, Internal Medicine, Infectious Disease

Keywords: sar-cov 2 infection, covid-related hypercoagulability, thrombo embolic disease, intracardiac thrombus, covid-19

\section{Introduction}

In December 2019, a new respiratory virus called severe acute respiratory virus syndrome (SARS-CoV-2) was first discovered in China. The disease caused by SARS-CoV-2 was named coronavirus disease 2019 (COVID19) [1] and it rapidly spread across the countries, resulting in a global pandemic. COVID-19 was thought to mainly affect the respiratory system. However, studies have shown that it can be associated with hypercoagulability leading to thromboembolism. Although venous thromboembolism is a common complication associated with COVID-19, arterial thrombosis and intracardiac thrombosis are not frequently described [2-4]. Herein, we report a case of a patient presenting to the emergency department with shortness of breath after recovering from COVID-19 a month ago and was found to have intracardiac thrombus.

\section{Case Presentation}

A 54-year old male with a past medical history of end-stage renal disease with hemodialysis on Tuesday, Thursday, and Saturday, diabetes mellitus, hypertension, heart failure, chronic obstructive pulmonary disease presented to the emergency department with shortness of breath for two days. The patient was admitted to the hospital for coronavirus disease 2019 (COVID-19) pneumonia one month ago and was discharged with 4 liters of nasal cannula oxygen. On this current visit, the patient's vital signs were as follows; temperature: $98^{\circ} \mathrm{F}$, blood pressure: $150 / 89 \mathrm{mmHg}$, pulse rate: $97 / \mathrm{min}$, respiratory rate: $28 / \mathrm{min}$, and oxygen saturation $95 \%$ with a non-rebreather mask. His coagulation profile showed PT of $13.7 \mathrm{~s}$, INR of 1.1 , and PTT of $30.2 \mathrm{~s}$. Laboratory studies were notable for the following: hemoglobin $6.5 \mathrm{~g} / \mathrm{dl}$, blood urea nitrogen $70 \mathrm{mg} / \mathrm{dl}$, creatinine $9.6 \mathrm{mg} / \mathrm{dl}$, and pro-BNP $40000 \mathrm{pg} / \mathrm{ml}$. The patient stated that he had intermittent dark stools after discharge from the hospital. Pantoprazole $40 \mathrm{mg}$ intravenous (IV) twice a day was started and a total of 4 units of packed red blood cells (PRBCs) were transfused throughout the hospital stay, after which hemoglobin went up to $9.5 \mathrm{~g} / \mathrm{dl}$.

Chest X-ray showed worsening of infiltrates from the prior visit study (Figure 1). An echocardiogram revealed mild to moderate global left ventricular hypokinesis with an ejection fraction of 45-50\%, grade 2 diastolic dysfunction, and a large $(1.1$ X $1.5 \mathrm{~cm})$ dense oval very highly mobile thrombus seen in the right ventricular cavity near the base (Figure 2). CT angiogram of the chest obtained to rule out pulmonary embolism came out negative. After endoscopy and colonoscopy revealed no source of bleeding, a heparin drip was started and the patient was transitioned to apixaban upon discharge for intracardiac thrombus. After a few rounds of hemodialysis throughout the hospital stay, the patient's respiratory status improved and the patient was discharged from the hospital. 


\section{Cureus}

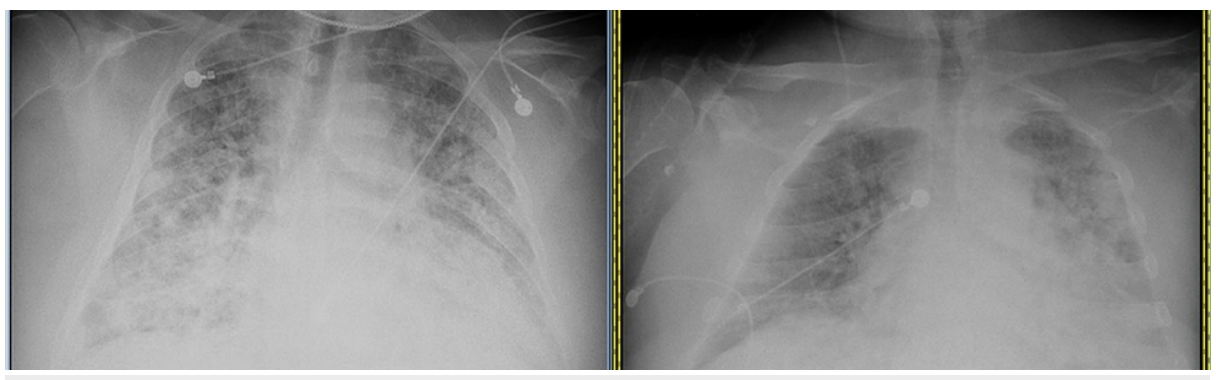

FIGURE 1: Chest X-ray showing worsening of infiltrates (A) from prior visit study (B)

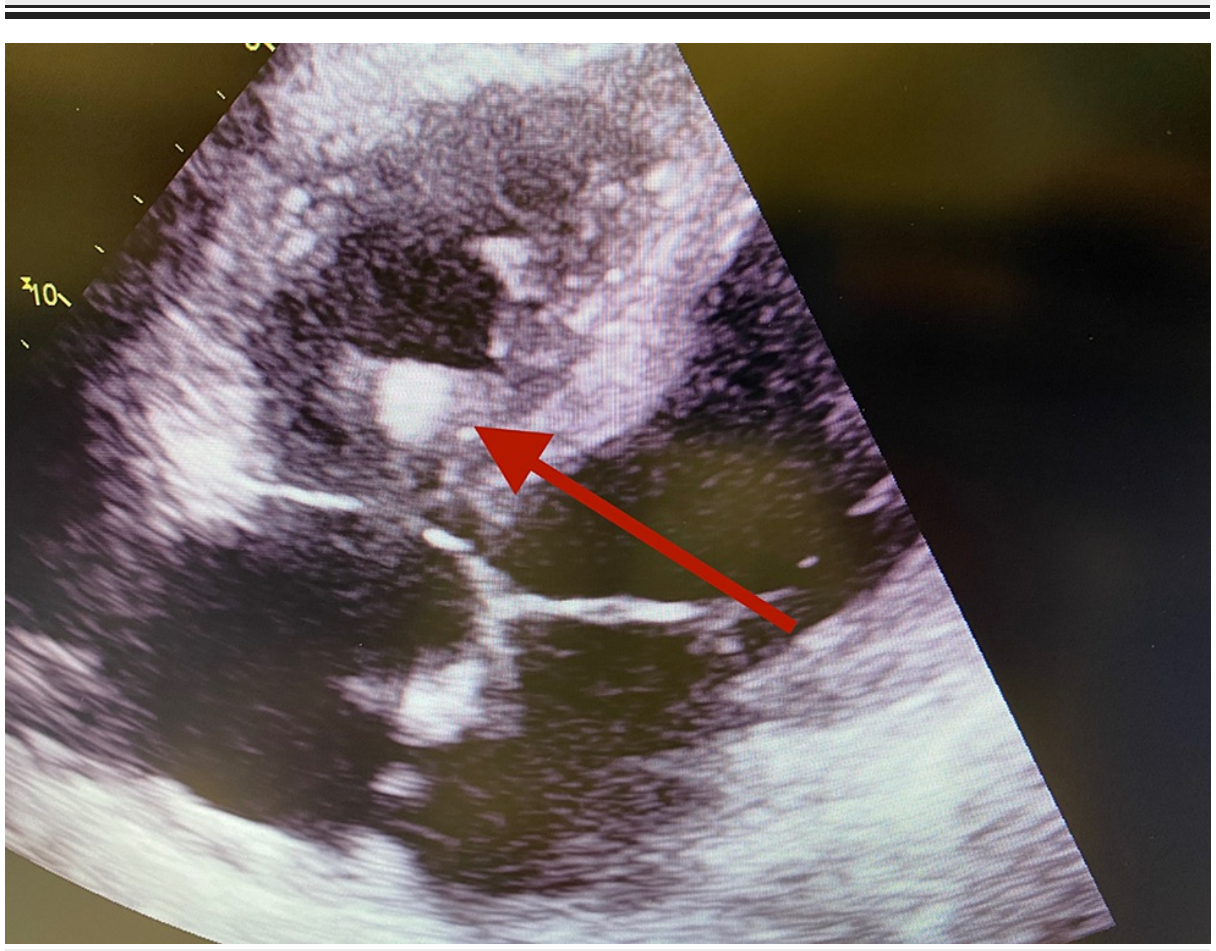

FIGURE 2: Echocardiogram showing intracardiac thrombus in right ventricle on subcostal view

\section{Discussion}

The clinical features of COVID-19 infection range from asymptomatic infection to critical and fatal illness. Cough, myalgias, and headaches are the most commonly reported symptoms. Other less commonly described symptoms include diarrhea, sore throat, and loss of smell or taste. COVID-19 mainly affects the respiratory system resulting in fever, cough, dyspnea, and pneumonia. Acute respiratory distress syndrome (ARDS) is the most common complication in severe disease $[5,6]$. Other commonly described complications include thromboembolic events, acute cardiac injury, kidney injury, and inflammatory complications.

Although COVID-19 is known to be associated with hypercoagulability, the pathophysiology behind it is still unclear. The proposed mechanisms include complement-mediated endothelial injury, venous stasis, and coagulation abnormalities. The contribution of complement-mediated endothelial injury has been suggested due to the activation of the alternative complement pathway by SARS-CoV-2 spike protein $[7,8]$. Furthermore, COVID-19-induced inflammatory response, including cytokines such as interleukin-6 (IL-6) and other cytokines, promote coagulability by mediating endothelial injury. Dysfunction of endothelial cells induced by COVID-19 infection leads to excess thrombin generation and fibrinolysis shutdown [9]. Immobilization can lead to stasis of blood flow in all critically ill patients, regardless of whether they have COVID-19. The hypothesis of coagulation abnormalities' contribution to hypercoagulability is based on increased levels of circulating prothrombotic factors found in COVID-19 such as elevated factor VIII, fibrinogen, circulating prothrombotic microparticles, and neutrophil extracellular traps (NETs) [10-12]. The hypoxia observed in severe COVID-19 can also stimulate thrombosis by increasing blood viscosity or by activation of the hypoxia-inducible factor-1 (HIF-1) signaling pathway leading to increased blood viscosity 
[13]. Studies have shown that COVID-19 related coagulopathy and complications lead to longer hospitalizations and death, and on the other hand, critically-ill patients often show an increased thrombotic diathesis (with higher D-dimer and lower fibrinogen values) [14-16]

An observational study reported that anticoagulation may be associated with improved outcomes in patients hospitalized with COVID-19 [17]. However, current guidelines do not recommend post-discharge prophylactic anticoagulation for COVID-19 unless patients have documented thromboembolism or have major prothrombotic risk factors [18]. Nevertheless, physicians should have a high index of suspicion of thromboembolic complications in recovering COVID-19 patients.

\section{Conclusions}

This case is distinctive because the discovery of intracardiac thrombus was in a patient recovering from COVID-19 illness as opposed to patients being acutely ill with COVID-19 as in other cases.

Hypercoagulability associated with COVID-19 is a growing field of research. This case highlights and adds to a growing body of literature regarding anticoagulant use and thromboembolic complications in recovering COVID-19 patients.

\section{Additional Information \\ Disclosures}

Human subjects: Consent was obtained or waived by all participants in this study. Conflicts of interest: In compliance with the ICMJE uniform disclosure form, all authors declare the following: Payment/services info: All authors have declared that no financial support was received from any organization for the submitted work. Financial relationships: All authors have declared that they have no financial relationships at present or within the previous three years with any organizations that might have an interest in the submitted work. Other relationships: All authors have declared that there are no other relationships or activities that could appear to have influenced the submitted work.

\section{References}

1. The species Severe acute respiratory syndrome-related coronavirus: classifying 2019-nCoV and naming it SARS-CoV-2. Nat Microbiol. 2020, 5:536-44. 10.1038/s41564-020-0695-Z

2. Kollias A, Kyriakoulis KG, Lagou S, Kontopantelis E, Stergiou GS, Syrigos K: Venous thromboembolism in COVID-19: A systematic review and meta-analysis. Vasc Med. 2021, 26:415-25. 10.1177/1358863X21995566

3. Wu C, Liu Y, Cai X, Zhang W, Li Y, Fu C: Prevalence of venous thromboembolism in critically ill patients with coronavirus disease 2019: A meta-analysis. Front Med (Lausanne). 2021, 8:603558. 10.3389/fmed.2021.603558

4. Mansory EM, Srigunapalan S, Lazo-Langner A: Venous thromboembolism in hospitalized critical and noncritical COVID-19 patients: A systematic review and meta-analysis. TH Open. 2021, 5:e286-94. 10.1055/s-0041-1730967

5. Chen N, Zhou M, Dong X, et al.: Epidemiological and clinical characteristics of 99 cases of 2019 novel coronavirus pneumonia in Wuhan, China: a descriptive study. Lancet. 2020, 395:507-13. 10.1016/S01406736(20)30211-7

6. Huang C, Wang Y, Li X, et al.: Clinical features of patients infected with 2019 novel coronavirus in Wuhan, China. Lancet. 2020, 395:497-506. 10.1016/S0140-6736(20)30183-5

7. Magro C, Mulvey JJ, Berlin D, et al.: Complement associated microvascular injury and thrombosis in the pathogenesis of severe COVID-19 infection: A report of five cases. Transl Res. 2020, 220:1-13. 10.1016/j.trsl.2020.04.007

8. Yu J, Yuan X, Chen H, Chaturvedi S, Braunstein EM, Brodsky RA: Direct activation of the alternative complement pathway by SARS-CoV-2 spike proteins is blocked by factor D inhibition. Blood. 2020, 136:2080-9. 10.1182/blood.2020008248

9. Begbie M, Notley C, Tinlin S, Sawyer L, Lillicrap D: The Factor VIII acute phase response requires the participation of NFkappaB and C/EBP. Thromb Haemost. 2000, 84:216-22.

10. Panigada M, Bottino N, Tagliabue P, et al.: Hypercoagulability of COVID-19 patients in intensive care unit: A report of thromboelastography findings and other parameters of hemostasis. J Thromb Haemost. 2020, 18:1738-42. 10.1111/jth.14850

11. Ranucci M, Ballotta A, Di Dedda U, et al.: The procoagulant pattern of patients with COVID-19 acute respiratory distress syndrome. J Thromb Haemost. 2020, 18:1747-51. 10.1111/jth.14854

12. Maier CL, Truong AD, Auld SC, Polly DM, Tanksley CL, Duncan A: COVID-19-associated hyperviscosity: a link between inflammation and thrombophilia?. Lancet. 2020, 395:1758-9. 10.1016/S0140-6736(20)31209-5

13. Gupta N, Zhao YY, Evans CE: The stimulation of thrombosis by hypoxia . Thromb Res. 2019, 181:77-83. 10.1016/j.thromres.2019.07.013

14. Wu C, Chen X, Cai Y, et al.: Risk factors associated with acute respiratory distress syndrome and death in patients with coronavirus disease 2019 pneumonia in Wuhan, China. JAMA Intern Med. 2020, 180:934-43. 10.1001/jamainternmed.2020.0994

15. Zhou F, Yu T, Du R, et al.: Clinical course and risk factors for mortality of adult inpatients with COVID-19 in Wuhan, China: a retrospective cohort study. Lancet. 2020, 395:1054-62. 10.1016/S0140-6736(20)30566-3

16. Tang N, Li D, Wang X, Sun Z: Abnormal coagulation parameters are associated with poor prognosis in patients with novel coronavirus pneumonia. J Thromb Haemost. 2020, 18:844-7. 10.1111/jth.14768

17. Paranjpe I, Fuster V, Lala A, et al.: Association of treatment dose anticoagulation with in-hospital survival 


\section{Cureus}

among hospitalized patients with COVID-19. J Am Coll Cardiol. 2020, 76:122-4. 10.1016/j.jacc.2020.05.001

18. COVID-19 and VTE/Anticoagulation: Frequently Asked Questions. (2021). Accessed: January 5, 2022: https://www.hematology.org/covid-19/covid-19-and-vte-anticoagulation. 